Foro Interno. Anuario de Teoría Política

ISSN: 1578-4576

\title{
Crítica al fundamentalismo electoral a través del mecanismo del sorteo: propuestas democráticas de Burnheim y Goodwin desde una perspectiva utópica
}

Gabriel Camarelles Queralt ${ }^{1}$

Recibido: 22 de enero de 2020 / Aceptado: 20 de octubre de 2020.

Resumen: El sorteo, practicado por primera vez en Atenas a principios del siglo V a. e. c., ha sido considerado durante mucho tiempo, por parte de la teoría política, como un importante mecanismo democratizador. Sin embargo, este recurso entró en desuso durante el desarrollo de la democracia moderna representativa a favor de las elecciones por votación, un fenómeno que algunos autores han calificado como "fundamentalismo electoral". El objetivo de este artículo es presentar, comparar y evaluar dos propuestas utópicas de democracia por sorteo ofrecidas por John Burnheim y Barbara Goodwin. La tarea que se plantea es analizar su validez y limitaciones, así como considerar su potencial de cara a mejorar las actuales democracias representativas.

Palabras clave: Fundamentalismo electoral, sorteo, utopía, deliberación, justicia distributiva.

\section{[en] A Critique of Electoral Fundamentalism through the Sortition Mechanism: The Democratic} Proposals of Burnheim and Goodwin Seen from a Utopian Perspective

\begin{abstract}
Sortition has for a long time been considered as an important democratizing mechanism in political theory. It was first practiced in Athens in the early 5th century BCE. However, sortition fell into disuse during the development of modern representative democracy, replaced by ballot box elections, a phenomenon which some authors labelled as "electoral fundamentalism". The objective of this article is to present, compare, and evaluate two so-called utopian proposals for democracy by lottery, offered by John Burnheim and Barbara Goodwin. The task at hand is to analyze their validity and limitations, as well as to consider their potential for improving today's representative democracies.

Keywords: Electoral fundamentalism, sortition, utopia, deliberation, distributive justice.

Sumario: 1. Introducción. 2. El sorteo y su potencial para la profundización democrática. 3. El concepto de utopía, el pensamiento utópico y su relación con las transformaciones de la ciencia política. 4. Demarquía: la utopía democrática de John Burnheim. 4.1. Problemas de la política electoral. 4.2. Demarquía. 5. Aleatoria: la sociedad utópica de Barbara Goodwin. 5.1. Las ventajas de la Lotería Social Total. 6. Problematicidad y límites teóricos de las propuestas de Burnheim y Goodwin. 7. Aplicaciones prácticas contemporáneas del uso del sorteo. 8. Conclusiones. 9. Referencias bibliográficas.
\end{abstract}

Cómo citar: Gabriel Camarelles Queralt, "Crítica al fundamentalismo electoral a través del mecanismo del sorteo: propuestas democráticas de Burnheim y Goodwin desde una perspectiva utópica”: Foro Interno. Anuario de Teoría Política, vol. 21 (2021), pp. 33-47.

\section{Introducción}

En las últimas décadas, la profundización democrática se ha convertido en uno de los temas cruciales de la teoría política contemporánea. En este sentido, el uso del sorteo en política ha experimentado un renacimiento sorprendente, tanto en el debate teórico como en la implementación, irrumpiendo como uno de los elementos transformadores capaces de fortalecer la democracia ${ }^{2}$. Cuando en la actualidad nos referimos a la democracia, generalmente, estamos hablando de democracia representativa electoral, cuyo elemento central son los partidos políticos $^{3}$. Un sistema democrático basado en una competición entre élites políticas que lucha por la transmisión

Universidad Jaume I de Castellón (España)

E-mail: gabycamarelles@hotmail.com

2 Hubertus Buchstein, "Countering the 'Democracy Thesis'- Sortition in Ancient Greek Political Theory": Redescripcions: Political Thought, Conceptual History and Feminist Theory, vol. 18, n. ${ }^{\circ} 2$ (2015), pp. 126-127; Ramón A. Feenstra, "Democracia y elección por sorteo en las nuevas formaciones políticas: teorías políticas clásicas y contemporáneas”: Daimon. Revista Internacional de Filosofia, n. ${ }^{\circ} 72$ (2017), p. 205.

3 Para el origen y consolidación de los partidos políticos, véase Maurice Duverger, Los partidos políticos, Fondo de Cultura Económica, México, 2012.

Foro interno 21 2021: 33-47 
representativa del poder a través de unas elecciones populares ${ }^{4}$. Esta estrecha relación entre democracia y elecciones ha suscitado numerosas críticas en contra de lo que se denomina fundamentalismo electoral ${ }^{5}$. Es decir, el reduccionismo de la democracia a limitar la participación de la ciudadanía al proceso electoral y poco más ${ }^{6}$. Sin embargo, en la democracia antigua, la elección solo se utilizaba en algunos supuestos excepcionales. En palabras de Aristóteles (384 a. e. c. - 322 a. e. c.): "Que las magistraturas se designen por sorteo, todas o las que no requieran experiencia y conocimientos técnicos" ". En este sentido, la elección era un recurso complementario al uso predominante del sorteo.

De ahí que en este artículo se busque explorar la vía del sorteo, consistente en poner en valor sus potencialidades a la hora de facilitar la participación de la ciudadanía en el proceso de toma de decisiones políticas. De esta forma, mediante el estudio de las propuestas utópicas-democráticas de John Burnheim y Barbara Goodwin, se pretende debatir unos principios mínimos que guíen la funcionalidad adecuada de los procesos y las instituciones democráticas, para la búsqueda del bien común $\mathrm{y}$, con ello, paliar la pérdida de confianza y el distanciamiento de la ciudadanía de la política, los políticos y las instituciones democráticas.

En primer lugar, se va a establecer el marco normativo del sorteo y su potencial para la profundización democrática y, en segundo lugar, se aborda el concepto de utopía, y la relación del pensamiento utópico con las transformaciones de la ciencia política. Este artículo de investigación se centrará, como punto de partida, en algunos aportes de las propuestas utópicas-democráticas de Burnheim y Goodwin, para intentar, al menos, minimizar algunos de los principales problemas que presentan las democracias representativas electorales contemporáneas. Para lograr la superación de algunas de las debilidades este sistema democrático, se presentarán tanto virtudes como las posibles limitaciones de ambas. Cabe mencionar que, ante la abundante diversidad conceptual del término utopía, se parte de aquel que la sitúa en un contexto temporal remoto y deseable, pero no imposible o inalcanzable en un futuro más o menos cercano. En este sentido se argumenta que, a lo largo de la historia reciente, algunas propuestas utópicas del pasado se han convertido en auténticas realidades con el paso del tiempo. Por este motivo, el cierre del artículo se dedicará a presentar una crítica constructiva del sorteo, y se analizará su aplicación en casos reales actuales, hecho que denota que el pensamiento utópico no siempre es tan utópico, en el sentido de irrealizable.

\section{El sorteo y su potencial para la profundización democrática}

Como señala Giovanni Sartori (1924-2017), la democracia de los griegos era una democracia directa y "todas nuestras democracias son indirectas, es decir, son democracias representativas en las que estamos gobernados por representantes, no por nosotros mismos"8. La selección de los cargos por sorteo es uno de los rasgos característicos de la democracia directa ateniense, que posibilita la participación política de la ciudadanía, juntamente con la rotación de cargos, la limitación de mandatos, la igualdad política, la deliberación pública, la responsabilidad y la ética cívica9.

La selección por sorteo, más que en otras ciudades griegas, fue un procedimiento habitual en Atenas. El uso de la selección aleatoria se desarrolló al mismo nivel con la propia democracia, y se utilizó masivamente en los siglos V y IV a. e. c., durante la edad dorada de la democracia ateniense ${ }^{10}$. Los atenienses eran conscientes de las limitaciones del uso del sorteo, como por ejemplo que la selección indiscriminada podría elevar a ciudadanos incompetentes a cargos públicos. Frente a este riesgo, y otros inconvenientes, llevaron a cabo arreglos institucionales complementarios ${ }^{11}$. Estos arreglos son las características institucionales que materializaban los ideales de la democracia ateniense, que hemos denominado principios mínimos, y pasamos a analizar brevemente.

El sorteo, la rotación y la limitación de mandatos servían de protección contra la profesionalización y la monopolización del poder en manos de las élites. Aristóteles describe que la esencia de la democracia es la libertad, y una de sus características es gobernar y ser gobernado por turno, y asignar los cargos por

Giovanni Sartori, Teoría de la democracia 2. Los problemas clásicos, Alianza editorial, Madrid, 1988, pp. 149-150; Joseph Schumpeter, Capitalismo, socialismo y democracia, vol. II, Folio, Barcelona, 1996, p. 321.

David Van Reybrouck, Contra las elecciones. Cómo salvar la democracia, Taurus, Barcelona, 2017, pp. 117-118.

El reduccionismo participativo defendido por la democracia elitista es superado por la democracia participativa al maximizar la participación de la ciudadanía en la gestión pública. Para el origen y desarrollo de la teoría participativa, véase Carole Pateman, Participation and Democratic Theory, Cambridge University Press, Cambridge, 1970.

Aristóteles, Política, Gredos, Madrid, 1988, L. IV, $1317 \mathrm{~b} 5$.

Sartori, Teoría de la democracia 2, pp. 345-346.

R. K. Sinclair, Democracia y participación en Atenas, Alianza editorial, Madrid, 1999, p. 42; Yves Sintomer, "Sorteo y política: ¿de la democracia radical a la democracia deliberativa?": Daimon. Revista Internacional de Filosofia, n. ${ }^{\circ} 72$ (2017), pp. 28-29; Adela Cortina, Ciudadanos del mundo. Hacia una teoría de la ciudadanía, Alianza editorial, Madrid, 1997, p. 39.

10 Véase Morgens H. Hansen, The Athenian Democracy in the Age of Demosthenes: Structure, Principles, and Ideology, University of Oklahoma Press, Oklahoma, 1999.

11 Bernard Manin, Los principios del gobierno representativo, Alianza editorial, Madrid, 1998, pp. 21-22. 
sorteo, facilita la igualdad política ${ }^{12}$. No obstante, se reconocía la necesidad de poseer dotes profesionales especializados en ciertos cargos $^{13}$. El sorteo tuvo que superar algunos inconvenientes, tales como la corrupción y la falta de participación de las clases trabajadoras. La medida que se implantó fue asignar un salario por participar en los asuntos públicos. Según Aristóteles, uno de los motivos principales para asignar un salario fue evitar la corrupción que devenía de la venta de $\operatorname{los} \operatorname{cargos}^{14} \mathrm{y}$, a su vez, favorecer la participación de las personas con menos recursos que dependían de su trabajo para subsistir ${ }^{15}$.

La participación y la deliberación en la sociedad ateniense estaban estrechamente relacionadas, ya que se interactuaba activamente en debates políticos cara a cara ${ }^{16}$. Pericles (495 a. e. c. - 429 a. e. c.) en su famosa oración fúnebre presenta a la sociedad ateniense como una comunidad participativa y deliberativa, en la cual el ciudadano no solo tenía el derecho de participar en la vida pública, sino que tenía el deber de hacerlo. De lo contrario, era tildado de inútil aquel que nada participaba en ella. Y la deliberación, más que la violencia, era el procedimiento más adecuado para tratar las cuestiones públicas ${ }^{17}$. En esta línea deliberativa, Aristóteles dirá que el hombre, frente a los demás animales, tiene el don de la palabra y la capacidad de relacionarse con otros hombres, y también de discernir lo justo y lo injusto, y poseer el sentido del bien y del mal y de los demás valores ${ }^{18}$.

La responsabilidad era un requisito ineludible, cualquier cargo público tenía que responder ante el pueblo. La responsabilidad estaba sujeta al requisito de someterse a un examen para dar cuenta de sus actuaciones políticas, y a una investigación en relación con sus actividades económicas al término de su mandato ${ }^{19}$. Había un calendario para rendir cuentas, y todo aquel que no lo hacía no podía acceder a un nuevo cargo ${ }^{20}$. De la rendición de cuentas aparecen dos elementos propios de la democracia ateniense: la asunción de responsabilidades y la revocación de mandato. Cuando un magistrado era condenado por su mala praxis debía asumir sus responsabilidades que podían llegar hasta su destitución; es decir, hasta la revocación de su mandato. Según Manin, la asunción de responsabilidades "podía alcanzar sumas considerables, llegando a endeudar a alguien con la ciudad para el resto de sus días y privándolo de sus derechos civiles (atimia)"”21.

Una de las virtualidades de la democracia clásica es el compromiso ético. La democracia ateniense se caracterizaba por un compromiso colectivo con el principio de la virtud cívica: la dedicación a la comunidad y la subordinación de la vida privada a la vida pública y al bien común ${ }^{22}$. Según Aristóteles, en la actividad política "se elogia el ser capaz de mandar y obedecer, y la virtud de un ciudadano digno parece que es el ser capaz de mandar y obedecer bien" 23 . Para el Estagirita la capacidad de mandar y obedecer constituía la virtud de los ciudadanos, y entendía que el gobernante debía aprender a ser gobernado, ya que no podía mandar bien aquel que no ha obedecido. Manin denomina a este principio justicia democrática: "Dado que aquellos dan órdenes algún día habrían tenido que obedecerlas, era posible que tuvieran en consideración en sus decisiones las opiniones de los afectados por las mismas" ${ }^{24}$.

\section{El concepto de utopía, el pensamiento utópico y su relación con las transformaciones de la ciencia política}

Alo largo de la historia, el término utopía ha aglutinado multitud de significados, muchos de ellos contradictorios, y otros relativos a distintas perspectivas que incrementan su diversidad conceptual. Según la concepción que se establezca de utopía, la idea se puede rastrear hasta los inicios de la historia de la humanidad. No obstante, la historia del concepto como tal se demorará hasta el siglo XVI. Es en 1516 cuando Tomás Moro (1478-1535) crea el término valiéndose del griego y dejando una ambigüedad que aún persiste en nuestros días: utopía es tanto ou-topos - no lugar - como eu-topos — buen lugar ${ }^{25}$ - . Esta dualidad da pie, en primera instancia, a dos interpretaciones: un lugar inexistente e irrealizable o un lugar bueno e idealizado. Más allá de profundizar en la prolífera diversificación del concepto, y para centrar el argumentario de nuestra investigación (lo utópico no es siempre tan utópico), se partirá de dos concepciones.

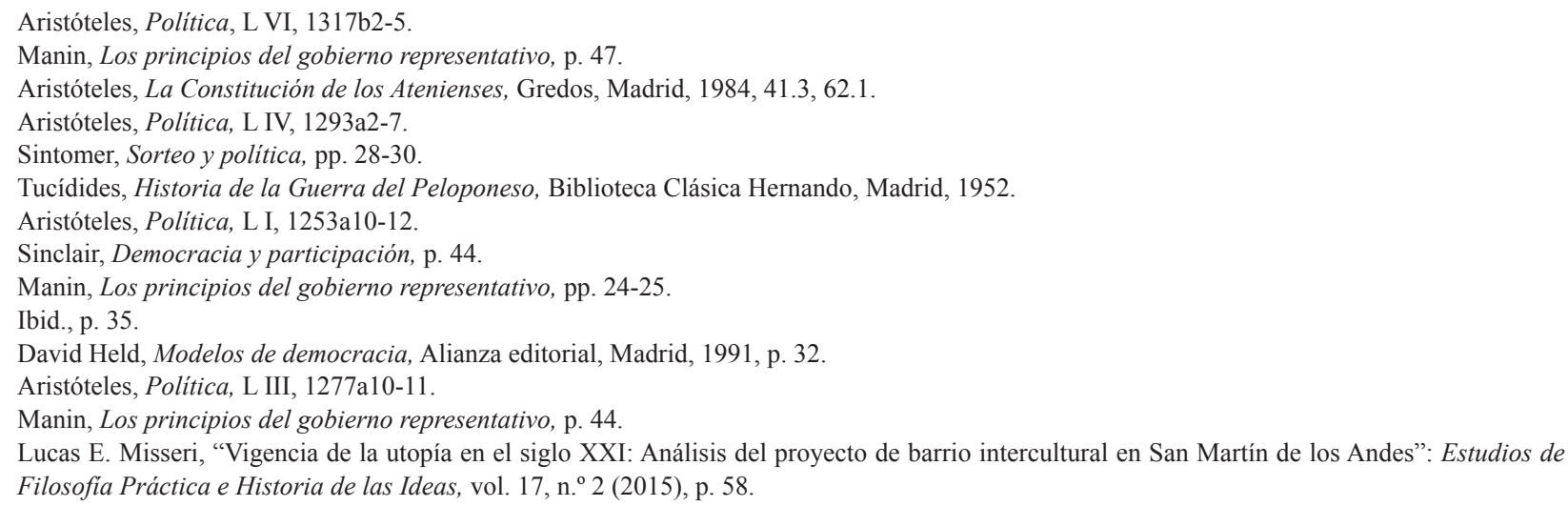


En la definición de utopía incluida en el diccionario de José Ferrater Mora (1912-1991), se expone que algunos autores de utopías las ven en un principio irrealizables "pero les mueve el deseo de criticar la sociedad de su época y el deseo de mejorarla. El motivo principal de las utopías es, pues, la voluntad de reforma"26. El diccionario de la Real Academia Española también deja abierta su posible realización: "Plan, proyecto, doctrina o sistema deseables que parecen de muy difícil realización"27. Por una parte, la utopía aparece como crítica social, voluntad de reforma y en un principio irrealizable y, por otra, como un proyecto o sistema deseable difícil de realizar, pero en ambos casos no aparece como imposible.

No es el propósito de este trabajo profundizar en todo el recorrido del pensamiento utópico, y su relación con las transformaciones en la ciencia política, sino más bien, esbozar algunas de las corrientes más significativas relacionadas, directa o indirectamente, con las dos propuestas utópicas de Burnheim y Goodwin.

El pensamiento utópico, con su idealismo político, sus profecías y, sobre todo, con su convicción en el cambio y la evolución social, además de una esperanza, constituye una finalidad en sí mismo, que ha florecido en momentos de necesidad. La literatura es una buena base para entender el proceso que ha seguido el pensamiento utópico a lo largo de la historia. El pensamiento utópico hunde sus raíces occidentales en la Ciudad ideal de Platón (427 a. e. c. - 347 a. e. c.), descrita en la República y las Leyes. Además, de esta fuente clásica bebe la tradición judeocristiana, sobre todo, en la Biblia: en las profecías de un Mesías en el Antiguo Testamento, y la idea del Milenio en el Nuevo Testamento ${ }^{28}$. Grosso modo, la utopía literaria se inicia con la República de Platón, que refleja la concepción ideal de un estado perfecto, expone reflexiones en torno a la política de su tiempo y propone una organización distinta que acabe con las injusticias y consiga la estabilidad de la sociedad.

El pensamiento utópico sufrió los tiempos oscuros de la Edad Media y prácticamente desapareció, si bien se mantuvo presente en la tradición judeocristiana con La ciudad de Dios de Agustín de Hipona (354-430) ${ }^{29}$. Es en el Renacimiento cuando la utopía introdujo su nombre. El pensamiento utópico adquirió su carta de naturaleza de la mano de Tomas Moro en 1516 de su obra Utopía, a la que seguirán La Ciudad del Sol (1623) de Tommaso Campanella (1568-1639) y La Nueva Atlántida (1627) de Francis Bacon (1561-1626) ${ }^{30}$. La Utopía de Moro vislumbra la posibilidad de superar el sistema de intereses particulares por una sociedad comunitarista, capaz de fomentar las relaciones fraternales y acabar con las desigualdades que provocaba el dinero y la propiedad privada. En este contexto nacía la utopía moderna y se daba comienzo a una tendencia política.

La consternación por las desigualdades provocadas por la Revolución Industrial, y la falta de practicidad de los ideales impulsados por la Revolución francesa, ocasionó la aparición del socialismo utópico, el socialismo científico y el anarquismo, con diferentes proyectos para aliviar la explotación obrera. La utopía renunció al carácter heredado de Moro (islas remotas e imaginarias) e irrumpió en la teoría sociopolítica en el mundo real ${ }^{31}$. El socialismo utópico fue encabezado por autores como Henri de Saint-Simon (1760-1825), Charles Fourier (17721837) y Robert Owen (1771-1858), que defendieron la idea de constituir una sociedad emancipada, capaz de garantizar la igualdad entre ciudadanos. El socialismo científico fue creado por Karl Marx (1818-1883) y Friedrich Engels (1820-1895), como respuesta a las propuestas del socialismo utópico, considerándolo una simple fantasía de la sociedad futura, que, si bien era útil por su componente crítico de la época, lo consideraban completamente irrealizable $^{32}$. Marx y Engels elaboraron un programa conocido con el nombre de Manifiesto Comunista, que promulgaba la teoría del socialismo científico no como una utopía irrealizable, sino como una revolución de los modos de producción tradicionales, capaz de eliminar las desigualdades que la propiedad privada y el capitalismo habían ocasionado a lo largo de la historia ${ }^{33}$. Entre los principales teóricos de la tradición utópica anarquista se encuentran Pierre Proudhon (1809-1865) ${ }^{34}$ y Mijaíl Bakunin (1814-1876) ${ }^{35}$, y en sus propuestas plantearán la eliminación del Estado y del Capitalismo, y harán una crítica a la teología.

\section{Demarquía: la utopía democrática de John Burnheim}

Burnheim, en la primera frase de la introducción de su libro Is Democracy Possible? The Alternative to Electoral Politics, realiza una afirmación muy contundente: "La democracia no existe en la práctica. En el mejor de los casos tenemos lo que los antiguos habrían llamado oligarquías electivas con fuertes elementos

José Ferrater Mora, "Utopía”, en Diccionario de filosofia, tomo II, 5ª ed., Editorial Sudamericana, Buenos Aires, 1964, p. 862.

Real Academia Española, "Utopía”, en Diccionario de la lengua española, 23ª ed., 2018.

Krishan Kumar, "Pensar utópicamente: política y literatura": Revista internacional de filosofía política, n. ${ }^{0} 29$ (2007), p. 67.

Jean Servier, Historia de la utopía, Monte Ávila Editores, Barcelona, 1969, p. 46.

Para profundizar en las utopías del Renacimiento véase Tomas Moro, Tomasso Campanella y Francis Bacon, Utopías del Renacimiento, estudio preliminar por Eugenio Imaz, trad. de Agustín Millares Carlo, Agustín Mateos, Margarita V. de Robles, Fondo de Cultura Económica, México, 2005.

31 Krishan Kumar, "El pensamiento utópico y la práctica comunitaria: Robert Owen y las comunidades owenianas": Política y sociedad, n. ${ }^{\circ} 11$ (1992), p. 126.

Ibid., pp. 127-128.

Karl Marx y Friedrich Engels, Manifiesto Comunista. Alianza editorial, Madrid, 2002.

Pierre Proudhon, Escritos Federalistas, Akal, Madrid, 2011.

Mijaíl Bakunin, Dios y el Estado, El viejo topo, Barcelona, 2008. 
monárquicos"36. A su juicio, el principal problema de la democracia electoral radica en la imposibilidad de aplicación del principio del gobierno del pueblo, para el pueblo y por el pueblo. Autores como Joseph Schumpeter (1883-1950) ${ }^{37}$ y Giovanni Sartori ${ }^{38}$, consideran que las elecciones son la esencia de la democracia. No obstante, Burnheim opina que "los sistemas electorales son enemigos de gobernar por el pueblo y para el pueblo"39. David Van Reybrouck es muy crítico con la democracia representativa electoral, y denomina fundamentalismo electoral a la creencia inalterable de que la democracia es impensable sin elecciones, a las que se consideran como el fundamento último de la soberanía popular ${ }^{40}$. Según Burnheim, el objetivo de votar "no es representar la variedad de intereses de quienes tienen voto, sino producir una decisión que será aceptada por casi todos como definitiva"41. A diferencia de las concepciones liberales o republicanas acerca de la democracia, su propuesta trata de garantizar que los afectados en un tema concreto tengan una buena representación de sus intereses y puedan intervenir en un proceso deliberativo ${ }^{42}$. No cabe duda de que este proceso deliberativo coincide en algunos principios con la propuesta de un modelo de democracia deliberativa expuesto por Jürgen Habermas ${ }^{43}$ entre otros.

En el presente apartado, se va a analizar la propuesta de demarquía de Burnheim. Para llevar a cabo dicho análisis, en primer lugar, se van a presentar los problemas que el autor identifica dentro de las democracias electorales actuales y, en segundo lugar, se va a estudiar su alternativa a las políticas electorales, un modelo de democracia por sorteo denominado demarchy (demarquía) para diferenciarla de la democracia electoral.

\subsection{Problemas de la política electoral}

Burnheim encuentra dos problemas principales que identifica con las democracias electorales. El primero es la democracia practicada por las élites. A su juicio, el proceso electoral desconecta la comunicación efectiva entre la ciudadanía y sus representantes políticos. El segundo problema lo encuentra en la profesionalización de la política, que aúpa al poder a un cuerpo que no es realmente representativo de la ciudadanía.

Una de las mayores dificultades que encuentra en las democracias electorales es el proceso de promoción de élites, y la distancia de estas una vez son elegidas en relación con las preferencias de sus representados ${ }^{44}$. En su opinión, la queja más común contra las democracias contemporáneas radica en la distancia entre los que toman las decisiones y los afectados por las mismas ${ }^{45}$, presentándose grandes desigualdades en la distribución del poder. En cuanto a la promoción de las élites, las personas con ideologías afines sobre la forma de gobernar o intereses compartidos se agrupan para constituir partidos políticos, a la vez que adquieren legitimidad para generar un gobierno, a partir de su participación directa en el proceso electoral. El gobierno se genera a partir de una competición entre las élites de los partidos rivales en busca de los votos necesarios del electorado para alcanzar el poder ${ }^{46}$. Sin embargo, Burnheim afirma que una vez elegido "un gobierno normalmente no está sujeto a revocación hasta que se produzca la próxima elección" ${ }^{47}$. A su juicio, el proceso electoral favorece el elitismo ${ }^{48}$ y minimiza la deliberación en el proceso de toma de decisiones públicas.

Para Burnheim la democracia electoral es reacia a dejar en manos de la ciudadanía la toma de decisiones o su implicación en las mismas. A su juicio "considerar las elecciones como un medio para elegir a los mejores representantes es esperar demasiado de ellos" 49 . Un problema que aparece con los políticos electos es que con frecuencia no cumplen sus promesas electorales, y aquellos que las mantienen, afirma, las presentan en momentos que ya no son apropiados. Por tanto, sostiene que la muestra representativa es un pilar de la democracia, ya que facilita que quienes toman las decisiones sean un microcosmos de las personas afectadas ${ }^{50}$. Sin embargo, rechaza las elecciones porque entiende que con ellas desaparece la democracia. Su solución pasa por retomar la antigua tradición democrática del sorteo ${ }^{51}$. En esta línea, Sintomer expone que la selección por

\footnotetext{
John Burnheim, Is Democracy Possible? The Alternative to Electoral Politics, University of California Press, California, 1985 , p. 1.

Schumpeter, Capitalismo, socialismo y democracia.

Sartori, Teoría de la democracia 2.

Burnheim, Is Democracy Possible?, p. 82.

Van Reybrouck, Contra las elecciones, pp. 51-52.

Burnheim, Is Democracy Possible?, p. 95.

Ibid., p. 5.

El principio del discurso de Habermas dice: "Sólo son legítimas aquellas normas de acción que pudieran ser aceptadas por todos los posibles afectados por ellas como participantes en discursos racionales”. Jürgen Habermas, Facticidad y validez, Trotta, Madrid, 1998, p. 9.

44 Burnheim, Is Democracy Possible?, p. 48.

45 El tema de la desafección de la ciudadanía con las instituciones de la democracia representativa es analizado por Peter Mair, Gobernando el vacio: la banalización de la democracia occidental, Alianza editorial, Madrid, 2015.

4 Sobre la lucha competitiva electoral para alcanzar el poder véase al respecto Schumpeter, Capitalismo, socialismo y democracia, pp. 343-360.

Burnheim, Is Democracy Possible?, p. 96.

48 El papel del elitismo en relación con la democracia es examinado en Peter Bachrach, Crítica de la teoría elitista de la democracia, Amorrortu editores, Buenos Aires, 1967.

Burnheim, Is Democracy Possible?, p. 99.

50 La muestra representativa es analizada como representación descriptiva por Hanna F. Pitkin, El concepto de representación, Centro de Estudios Constitucionales, Madrid, 1985 .

51 La propuesta de una cámara seleccionada por sorteo y la otra por elección para el Congreso de los Estados Unidos ha sido defendida por Ernest
} 
sorteo favorece el autogobierno de todos por todos, "esto significa que las tareas de gobierno ya no se confían a los «mejores», a una élite social o políticos profesionales" $"$.

Burnheim sostiene que el proceso electoral, salvo en cargos muy específicos, no garantiza que salgan elegidos los legisladores y administradores más capacitados. En su caso, las personas más aptas y mejores abandonan su interés por la política porque no están preparados para lidiar con las continuas maniobras partidistas de lucha de poder, desacreditar a sus cooperadores o abdicar ante las estrategias del partido ${ }^{53}$. Según Burnheim: "La política electoral engendra la política de partido, y la política de partido engendra la mediocridad y la corrupción ${ }^{54 "}$.

Burnheim ve como alternativa a los problemas de la democracia electoral la negociación en un entorno cooperativo a través del mecanismo del sorteo. En un proceso de toma de decisiones, la solución pasa por tomar en consideración la opción de hacer concesiones por todas las partes implicadas. El principio de reciprocidad es importante durante el proceso de negociación, ya que se pueden obtener ventajas o soluciones a largo plazo que puedan ser consideradas como justas para todos los implicados. Para Burnheim: "La negociación implica intentos de construir paquetes integrales a través de un proceso de exploración de posibilidades ... tratando de aclarar qué es importante y qué es negociable para cada parte" "55. Es decir, los paquetes integrales facilitarían que prevalecieran las preferencias reales de las personas sobre un asunto determinado.

Otro de los problemas más importantes en el cual pone el acento Burnheim se encuentra en la profesionalización de la política ${ }^{56}$, que comporta una evidente falta de representación política. A su juicio, muchas personas que aspiran a un cargo político tratan de vincularlo a su carrera profesional. Aquellos que realizan los programas políticos, cada vez son más profesionales y tratan de organizar y utilizar el poder para prosperar en sus carreras, lo que requiere una predisposición a realizar concesiones para alcanzar acuerdos políticos a toda costa en detrimento de la representación democrática. Para Burnheim, el problema de la profesionalización se agudiza cuando el electorado es un grupo estable y relativamente homogéneo, ya que presenta debilidad y pierde cualquier tipo de influencia. En este sentido, los líderes impondrán sus propias propuestas a las de sus seguidores reduciendo sus opciones a un todo o nada ${ }^{57}$.

La profesionalización de la política se ha ido imponiendo como una norma esencial de la democracia. Como señala Moreno-Pestaña: "Estamos acostumbrados a asociar el debate con los profesionales y entre personas que saben" ${ }^{\text {. }}$. Al parecer, la profesionalización de los cargos públicos se enfrenta a una clara dicotomía: realizar una buena política en general, o elegir asegurar su propio puesto dentro del partido político y medrar en sus carreras. Una solución a este tipo de inconvenientes partidistas se encuentra en la selección de un cargo político por sorteo. En palabras de Burnheim: "Si se logra un cargo público por sorteo, no hay carreras políticas profesionales. Nadie tiene que contraer deudas con organizaciones o patrones del partido para obtener un cargo o aferrarse a él" 59 .

El sorteo en sí no puede evitar posibles sobornos a los cargos públicos; no obstante, señala, los representantes no tendrían presiones ante la reelección, y tendrían las manos libres para estudiar diversas propuestas a favor de la calidad democrática. Incluso, podrían permitirse adoptar medidas impopulares para una mayoría de personas, pero que favorecieran los intereses de una minoría marginada. A su vez, el uso de la retórica en el discurso político perdería toda su fuerza de convicción, a favor de preferir ser reconocido no por sus palabras sino por la realización de un trabajo bien hecho ${ }^{60}$. En este sentido, para intentar evitar la distancia entre lo que la ciudadanía propone y lo que sus representantes deciden, Burnheim sostiene que hay que encontrar una forma en la que el pueblo decida primero qué es lo que se debe hacer y, más tarde, realizar un control a sus representantes durante el proceso de llevarlo a cabo. Hay que abandonar la entrega del consentimiento ${ }^{61}$, o la convención sin condiciones, e impulsar la decisión del grupo de personas bien informadas sobre el tema a

Callenbach y Michael Phillips en A Citizen Legislature, Banyan Tree Books, Berkeley, 1985. Otra propuesta dirigida a la Cámara de los Comunes en el Reino Unido ha sido presentada Keith Sutherland, en People's Parliament, Academic, Exeter, 2008. Una idea más radical que solo utiliza el sorteo y prescinde de las elecciones se encuentra en el artículo de Alexander A. Guerrero, "Against Elections: The Lottocratic Alternative": Philosophy \& Public Affairs, vol. 42 (2014), pp. 135-178. Para una visión más general de los argumentos a favor del sorteo veáse a Gil Delannoi y Oliver Dowlen en Sortition: Theory and Practice, Imprint Academic, Exeter, 2010.

2 Sintomer, "Sorteo y política", p. 39,

53 El protagonismo de los partidos políticos en la democracia moderna es estudiado en Robert Michels, Los partidos políticos. Un estudio sociológico de las tendencias oligárquicas de la democracia moderna, Amorrortu editores, Buenos Aires, 2 vols., 1969-1972.

54 Burnheim, Is Democracy Possible?, p. 101.

Ibid., p. 106.

56 Max Weber realiza una interesante reflexión sobre dos formas de hacer de la política una profesión: vivir "para” la política o vivir "de" la política, Max Weber, "La política como vocación” (1919), en El político y el cientifico, intr. de Raymond Aron, trad. Francisco Rubio Llorente, Alianza editorial, Madrid, 2003, pp. 81-180.

57 Burnheim, Is Democracy Possible?, pp. 97-98.

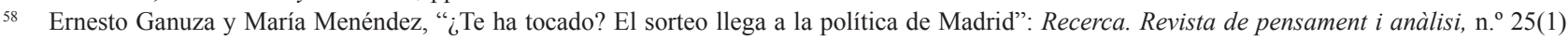
(2020), p. 4.

59 Burnheim, Is Democracy Possible?, p. 116.

60 Ibid., pp. 116-117.

61 Las concepciones modernas del derecho natural de la teoría del consentimiento o voluntad de los gobernados como fuente de autoridad legítima y principio fundamental de la obligación política son analizadas por Bernard Manin en Principios del gobierno representativo, Alianza editorial, Madrid, 1998. 
tratar. Dicho grupo de personas debe mantener una fuerte motivación para buscar la mejor solución posible y, sobre todo, ser representativas de los intereses compartidos por todo el grupo ${ }^{62}$.

Tras realizar un análisis de los principales problemas que Burnheim identifica dentro de las democracias representativas electorales actuales y las soluciones que aporta, a continuación, se va a profundizar en su propuesta democrática basada en el sorteo.

\subsection{Demarquía}

Burnheim, usando el término demarquía (demarchy), propone un sistema político que prescinda del Estado y la burocracia, en el cual grupos seleccionados por sorteo lleven a cabo la toma de decisiones públicas. Su finalidad es crear una alternativa democrática que supere la centralización y los problemas que presenta la política electoral, que pasa por establecer agencias funcionales especializadas autónomas e independientes. A su vez, presenta la demarquía como un proyecto utópico, a no ser, añade, que suficientes personas estén dispuestas a intentar realizarlo. De todos modos, encuentra pocas posibilidades de que se pueda realizar. No obstante, está convencido que algunas de las características del modelo no son nada utópicas sino todo lo contrario, son viables y se pueden llevar a cabo en la actualidad ${ }^{63}$. Su propuesta democrática pasa por la creación de un sistema democrático sin elecciones, la abolición de la profesionalidad de los cargos y la instauración de la membresía por sorteo, con la subsiguiente rotación de cargos y abierto al escrutinio público para establecer mejores condiciones para la participación y deliberación ciudadana ${ }^{64}$. La demarquía apuesta por la deliberación y presenta dos elementos para tener en cuenta: la descentralización funcional y el uso del sorteo.

La descentralización funcional es la propuesta de Burnheim para acabar con la centralidad de las funciones políticas del gobierno; es decir, más allá de que la toma de decisiones esté controlada centralmente por agencias multifuncionales - desde Estados-nación hasta municipios-, apuesta por comités ${ }^{65}$ independientes especializados $^{66}$ que se coordinen y negocien entre ellos. Según su criterio de esta manera también se pueden producir enfrentamientos que no dejen que se llegue a un consenso; por lo tanto, en el caso de que aparezcan problemas que no se puedan superar por estas agencias autónomas, su solución no pasa por que el proceso se dirija por un organismo de control centralizado, sino que más bien se lleve a cabo un arbitraje de tipo cuasi-judicial. A su vez, la participación en el proceso de la toma de decisiones en cada uno de los comités funcionales no contemplaría a la gente en general, sino que más bien se constituirían por los interesados según el tipo temáticas o asuntos por los que se ven afectados ${ }^{67}$.

El segundo elemento que presenta la demarquía es el sorteo y la representación estadística. Burnheim afirma que para tener democracia se debe retomar la antigua tradición de la selección por sorteo, a cambio de abandonar el sistema de elecciones. A su juicio, los órganos que desempeñan la toma de decisiones públicas deben estar constituidos por los afectados por sus decisiones, a partir de un muestreo estadísticamente representativo. Este es el principio de la demarquía, ya que la práctica electoral comporta inherentemente a la generación de oligarquías $^{68}$. La rotación de cargos por sorteo, continúa, era un mecanismo ampliamente considerado; sin embargo, la democracia se ha identificado con un proceso de elecciones competitivas a través del sufragio universal ${ }^{69}$. La rotación de los cargos en períodos regulares favorecería que se sumaran todo tipo de propuestas y sugerencias, avaladas por su relevancia intrínseca y no por intereses creados, ya que los representantes no estarían presionados por tener que someterse a la reelección ${ }^{70}$. El sorteo se presenta como un sistema de elección menos complicado que el electoral para ocupar un cargo, ya que desaparece la problemática a la hora de hacer costosas campañas, comprometer apoyos y el duro enfrentamiento que se produce en la competición electoral. A su vez, continúa, el sorteo favorece que la gente común tenga alguna posibilidad de acceder a un cargo público, hecho que en el sistema electoral es más propicio para un selecto número de personas.

Burnheim apuesta por una representación estadística y propone que los representantes no deben ser seleccionados por un sistema electoral basado en el voto mayoritario, sino que debe emplearse un mecanismo de selección aleatorio sobre un grupo de participantes posibles; es decir, a partir de un proceso de muestreo estadístico $^{71}$. Además, este grupo de candidatos debería regirse por la voluntariedad. Burnheim encuentra

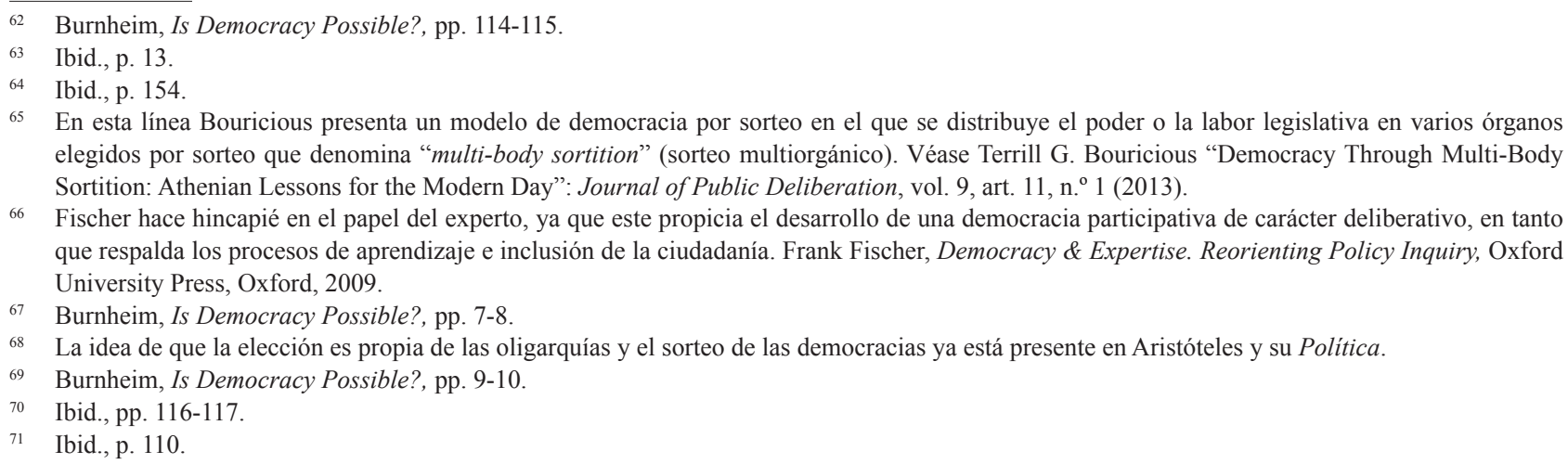

${ }_{66}$ Fischer hace hincapié en el papel del experto, ya que este propicia el desarrollo de una democracia participativa de carácter deliberativo, en tanto que respalda los procesos de aprendizaje e inclusión de la ciudadanía. Frank Fischer, Democracy \& Expertise. Reorienting Policy Inquiry, Oxford University Press, Oxford, 2009.

Burnheim, Is Democracy Possible?, pp. 7-8.

La idea de que la elección es propia de las oligarquías y el sorteo de las democracias ya está presente en Aristóteles y su Política.

Burnheim, Is Democracy Possible?, pp. 9-10.

Ibid., pp. 116-117.

Ibid., p. 110. 
más razonable para el grupo de interés que las personas voluntarias elegidas al azar sean aceptadas como representantes en la toma de decisiones ${ }^{72}$. A su juicio, la voluntariedad es un principio ineludible, ya que la obligatoriedad puede llevar a la apatía y la apatía a la dejadez en sus funciones. A su vez, afirma que los representantes elegidos a través de un muestreo estadístico dejarían de ser responsables bajo la ley penal, por el mero hecho de que no serían elegibles para un nuevo cargo.

Tras realizar una mirada a la propuesta democrática de Burnheim, se evidencia por qué se cataloga como utópica. Hasta el mismo autor acepta su sentido utópico, aunque a su vez, y hasta ahí se podría llegar a un consenso, cree que algunas de sus propuestas se podrían llevar a cabo en nuestras democracias actuales. Eso sí, añade, con una gran dosis de voluntad política.

\section{Aleatoria: la sociedad utópica de Barbara Goodwin}

El libro de Barbara Goodwin Justice by Lottery — en gran parte de teoría política — comienza con una pequeña historia que describe la sociedad utópica de Aleatoria, donde todo es distribuido por la "Lotería Social Total", desde los trabajos, pasando por las viviendas, hasta los castigos. La tesis principal que defiende la autora es que la justicia se puede lograr a través de la lotería. La propuesta se basa en la constitución de una Cámara de Representantes elegida al azar, ya que sostiene que la selección por sorteo daría una representación más justa a los grupos minusvalorados (mujeres, negros, hispanos, etc.) tradicionalmente marginados políticamente por un sistema político dominado por el dinero ${ }^{73}$. En este sentido, la propuesta de Goodwin se puede considerar hasta cierto punto como radical, si se compara con el modelo tradicional de las democracias representativas electorales contemporáneas.

Aleatoria lleva a cabo un sistema neodemocrático cuyos representantes son seleccionados al azar y por un período limitado de tiempo. Es decir, se practica el sorteo y la rotación de cargos. Como señala Goodwin, el sistema político de Aleatoria "se asemeja a lo que se nos dijo que existía en Atenas en la época clásica, y consideramos esto como una nueva Edad de Oro ${ }^{74}$ ". La propuesta de Goodwin tiene como objetivos principales eliminar la profesionalidad y la formación de élites en la política. A su juicio, la profesionalidad y la formación de élites repercute directamente en que la ciudadanía no se sienta identificada con sus representantes al producirse un conflicto de intereses que, por lo general, siempre beneficia a una parte privilegiada de la población. Se podría convenir que ambos factores repercuten directamente en favorecer el distanciamiento de la ciudadanía con la clase política e instituciones democráticas.

Uno de los principales retos de las democracias representativas electorales actuales pasa por paliar el creciente distanciamiento de la ciudadanía con sus representantes políticos. La profesionalización de la clase política y la influencia de las élites económicas en la agenda gubernamental son unos de los factores que favorecen dicho distanciamiento. En relación con la profesionalización de la clase política, Philippe Schmitter expone:

Hoy en día, los políticos necesitan de amplios recursos partidarios y personales para ganar las elecciones. Requieren un conocimiento especializado a fin de tener tecnócratas responsables y deben rodearse ellos mismos de expertos en encuestas de opinión con el fin de permanecer en sus cargos. El crecimiento de la clase política profesional puede ser inevitable, pero también es una de las fuentes más serias de desencanto ciudadano con la democracia real. La brecha social y cultural entre los ciudadanos y aquellos que claman por representarlos es un serio problema, ya que la dependencia creciente de los políticos sobre los fondos públicos crece a partir de fuentes - como mayores impuestos o sospechosos contribuyentes privados- que despiertan en la ciudadanía resentimiento o desconfianza ${ }^{75}$.

En cuanto a la influencia de las élites en la escena política, José Saramago ofrece una visión clarificadora:

Si la democracia fuera realmente el gobierno del pueblo, para el pueblo y por el pueblo, todo debate cesaría... el poder, el verdadero poder, se encuentra en otra parte: es el poder económico... los pueblos no han elegido a sus gobiernos para que éstos los "ofrezcan" al mercado. Pero el mercado condiciona a los gobiernos para que éstos les "ofrezcan" a sus pueblos. En nuestra época de mundialización liberal, el mercado es el instrumento por excelencia del único poder digno de ese nombre, el poder económico y financiero. Éste no es democrático puesto que no ha sido elegido por el pueblo, no es gestionado por el pueblo y sobre todo porque no tiene como finalidad el bienestar del pueblo ${ }^{76}$.

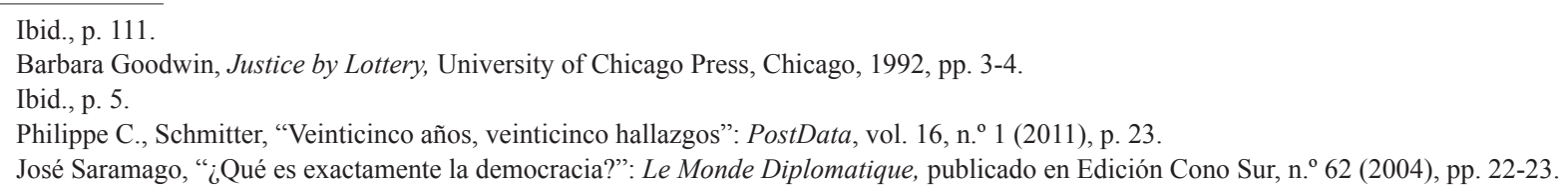


Goodwin a través de modelo ideal de Aleatoria busca la igualdad en la sociedad, y se practica el sorteo para generar una distribución justa de las cargas políticas, y dar a todos la misma oportunidad de participar en los órganos de gobierno. La autora incluye el sorteo en todas las ramificaciones del Estado: "Así como la tarea del gobierno se asigna al azar, también lo hacen los diversos cargos públicos que cualquier estado requiere que se lleven a cabo" 77 . A su vez, justifica su propuesta en que combate la profesionalización de la política, el secretismo y la corrupción. Sin embargo, Goodwin pone sobre el tapete un tema controvertido para los detractores del sorteo: la igualdad de competencias o capacidades de la ciudadanía para desempeñar cargos importantes ${ }^{78}$. Su solución pasa por llevar a cabo un proceso de instrucción intensiva ${ }^{79}$. Dicho proceso prepararía a las personas con capacidad media para poder llevar a cabo las tareas realizadas por expertos o profesionales, y la rotación por sorteo facilitaría el desarrollo de estos ${ }^{80}$. De la propuesta de Goodwin se puede extraer que en su búsqueda de la justicia social los mecanismos de la lotería y la rotación conforman la base fundamental para poder llevarse a cabo.

Un aporte de la propuesta de Goodwin es la "Lotería de los Paquetes de Estilo de Vida" que cambia radicalmente el modelo de vida de la democracia electoral basado en el binomio méritos-ingresos. Cada cinco años, la "Lotería de los Paquetes de Estilo de Vida" establece qué ingresos y qué tipo de vivienda percibirá una persona sin atender a sus méritos. Es decir, la contribución de cada uno en el trabajo no está relacionada con una posible recompensa, ya que a través de una rotación quinquenal por lotería puede cambiar radicalmente su estilo de vida: trabajo, ingresos, vivienda, etc. En Aleatoria también funcionan otras loterías: la "Lotería de la Rarezas", en la que los bienes escasos son repartidos aleatoriamente; o la "Lotería de la Maternidad", que asigna a las mujeres el derecho de tener un hijo al azar; y la "Lotería Penal", donde se distribuyen boletos entre los delincuentes con diferentes grados de castigo ${ }^{81}$. Al detenerse en las distintas propuestas de lotería de Goodwin se ponen de manifiesto los problemas que podrían surgir de tomar estas medidas al azar. Sin embargo, no cabe duda de que a su vez dejan al descubierto los graves problemas que ya existen sin las mismas en las democracias actuales. Se podría convenir que la propuesta de Goodwin más que un proyecto democrático al uso, de ahí su calado utópico, es un toque de atención para reflexionar hacia dónde nos lleva el modelo democrático liberal predominante en nuestras sociedades.

Goodwin sostiene que, contrariamente a la lotería y a la rotación, las democracias representativas electorales no promueven la realización política individual ni la igualdad de la carga política y, a su vez, favorecen la corrupción, la tiranía y el abuso de poder ${ }^{82}$. A su juicio, la democracia liberal no puede garantizar la limitación de los mandatos, a la vez que excluye, por lo general, a los partidos minoritarios; y algunos movimientos políticos con pocos seguidores nunca pueden obtener representantes elegidos. A su vez, continúa, la posesión del poder se convierte en un privilegio, una profesión o una función especializada; con lo cual, un grupo reducido de personas evitan que se produzca el intercambio de experiencias y conocimientos políticos, que surgen de la participación de toda la ciudadanía ${ }^{83}$.

Como expone Goodwin, la idea utópica de la rotación en el gobierno ha sido debatida desde el siglo XVII, antes de la Ilustración, hasta nuestros días. Entre los autores y autoras que destaca se encuentran James Harrington (1611-1677) con su utopía Oceana (1656); Robert Owen (1771-1858) y su propuesta para aldeas de cooperación; Goodwyn Barmby (1820-1881) en su utopía Platonopolis (1846) y Marge Piercy con su Woman on the Edge of Time (1979). En general, estos utopistas recurren a la rotación como un método para mejorar el desarrollo de la democracia. Según Goodwin, los utopistas de la rotación presentan dos formas para llevarse a cabo. La primera es la rotación de todos los ciudadanos elegibles en el poder y, la segunda, la rotación de las obligaciones entre los funcionarios públicos para evitar la corrupción, el mal gobierno y la promoción de los intereses privados o de las élites. A su juicio, tanto la rotación como la selección por lotería reflejarían los intereses del pueblo. Por tanto, defiende ambas posturas. Por una parte, Goodwin sostiene que la lotería (teniendo en cuenta el gran número de personas de las sociedades industriales modernas y de gran escala y los escasos puestos políticos y públicos) ofrecería un mecanismo distributivo más justo, si bien precisa de un

Goodwin, Justice by Lottery, p. 6.

Schumpeter defiende un modelo elitista de la democracia que exige un alto nivel de capacitación de los representantes electos y desconfía de la capacidad participativa de la ciudadanía en la esfera política, afirmando que: "El ciudadano normal desciende a un nivel inferior de prestación mental tan pronto como penetra en el campo de la política. Argumenta y analiza de una manera que él mismo calificaría de infantil si estuviese dentro de la esfera de sus intereses efectivos. Se hace de nuevo primitivo". Schumpeter, Capitalismo, socialismo y democracia, p. 335.

79 Barber es un defensor de la educación política de la ciudadanía. A su juicio, la comunidad crece desde la participación que, a su vez, potencia su autoaprendizaje para la vida política, mientras que la política se convierte en su propia Universidad. Benjamin Barber, Democracia fuerte, Editorial Almuzara, Córdoba, 2004, p. 222.

Goodwin, Justice by Lottery, p. 9.

Ibid., pp. 12-21.

Ibid., p. 130.

Para un análisis sobre la diversidad cognitiva y el aumento de la inteligencia colectiva —epistemología de la inclusión— véase Hélène Landemore "Deliberation, Cognitive Diversity, and Democratic Inclusiveness: an Epistemic Argument for the Random Selection of Representatives": Synthese, vol. 190, n. ${ }^{\circ} 7$ (2013), pp. 1209-1231. 
elevado número de personas; por otra, debido a esta circunstancia la rotación se presenta como más apropiada, ya que facilitaría la participación de toda la ciudadanía a largo plazo ${ }^{84}$.

\subsection{Las ventajas de la Lotería Social Total}

Según Goodwin, la "Lotería Social Total" favorece el aumento de la igualdad real debido al efecto que tendría la democracia por sorteo en cuanto a la disminución de las injusticias y las desigualdades ${ }^{85}$. El principio de igualdad es el elegido para demostrar la justicia. En un primer momento, al permitir que toda la ciudadanía pueda acceder en términos de igualdad al proceso de selección y, a continuación, que cada persona pueda experimentar en igualdad diferentes opciones de vida. La "Lotería Social Total" se fundamenta en el principio de igualdad. Sin embargo, ¿todos los estratos de la sociedad serían partidarios de esta?, o a escala global, ¿los países ricos apostarían por una lotería global? Goodwin opina que las clases privilegiadas o los países ricos no verían adecuada su implantación. Sin embargo, para los países pobres, la mayoría de los países del mundo, sería una práctica popular. En este sentido, la autora sostiene que ese es uno de los principales problemas que preocupan a los partidarios de la justicia social: el problema de los pobres y de aquellas personas que se quedan atrás ${ }^{86}$. A su juicio, las sociedades actuales no se rigen por el principio de igualdad, sino que apuestan por los mercados competitivos como la clave de la prosperidad y la libertad. Los políticos tienden a equiparar la distribución del mercado con recompensas justas atendiendo al talento o los méritos y la contribución ${ }^{87}$.

Goodwin entiende que su propuesta de la "Lotería Social Total" de Aleatoria se puede considerar por algunas personas como una sátira, que refleja que la búsqueda incontrolada de la justicia social, por encima de todos los demás bienes, llevaría a una sociedad con falta de libertad y miseria general. Sin embargo, defiende que siendo posible que "Lotería Social Total" no llegue a alcanzar la igualdad absoluta, sí que consigue la igualdad de oportunidades para todos y la igualdad aproximada de resultados, entendida como igualdad de oportunidades de vida. A su vez, Goodwin matiza que "a largo plazo conduciría hacia la igualdad absoluta, pero esta progresión siempre estaría limitada por la escasez, la diversidad y la posicionalidad de los bienes" ${ }^{88}$. La autora considera que tal vez la "Lotería Social Total" aleatoriana sería una forma de organización social menos eficiente que la sociedad actual de libre mercado. En este sentido, aboga por una justicia basada en valores para solucionar las cuestiones que entren en conflicto. Digamos que el proyecto utópico de Goodwin termina con una nueva utopía: alcanzar una sociedad que priorice realmente los valores humanos.

\section{Problematicidad y límites teóricos de las propuestas de Burnheim y Goodwin}

Al realizar una breve mirada a las propuestas utópicas-democráticas de Burnheim y Goodwin, hemos observado algunas coincidencias a la hora de presentar algunos de los principales problemas que adolecen las democracias representativas electorales actuales. En concreto, el elitismo y la profesionalización de la política, que enturbian el proceso político favoreciendo la manipulación, la corrupción, la usurpación y la concentración de poder. A su vez, han continuado los paralelismos en cuanto a su posible solución a largo plazo, a través de abandonar el proceso electoral a favor del uso del sorteo, la rotación y la limitación de mandatos. Ambas propuestas, aunque se desarrollan en contextos diferentes, presentan dos elementos clave presentes en la tradición utópica: crítica político-social de la sociedad de su tiempo y espíritu reformista. Sin embargo, mientras la propuesta de Goodwin se sitúa en la tradición utópica clásica y renacentista, idealizando una sociedad ideal en un país imaginario llamado Aleatoria; el argumentario de la propuesta de Burnheim encaja perfectamente en la tradición utópica anarquista, ya que defiende un sistema de toma de decisiones tanto en política como en economía como una alternativa al estado y la burocracia. Estas diferencias no suponen en ningún caso un distanciamiento en cuanto al fondo teórico de las mismas; es decir, ambas propuestas defienden de una u otra manera una democracia al estilo ateniense donde se prioriza el sistema del sorteo frente al sistema electoral actual. En este sentido, ¿las propuestas de Burnheim y Goodwin proyectan los principios mínimos de la democracia ateniense? En caso contrario ¿Qué grado de problematicidad y limitaciones presentan?

En términos generales, las propuestas de Burnheim y Goodwin recogen gran parte de las características de la democracia ateniense: sorteo, rotación y limitación en los cargos, igualdad política y deliberación pública. Pero ¿cómo abordan la cuestión de la responsabilidad pública y la ética cívica? La responsabilidad de los cargos públicos en la sociedad ateniense se justificaba a través de la rendición de cuentas, que podía llevar hasta la revocación de mandato, con severos castigos a los que hicieran un mal uso de su cargo.

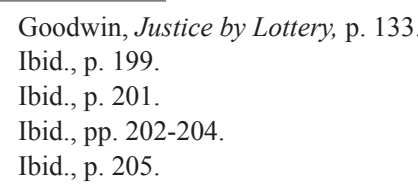


Burnheim realiza una crítica exhaustiva de la política electoral, el estado y la burocracia, y propone el sorteo y la diversidad de cuerpos funcionales. Sin embargo, si bien entrega el poder de la toma de decisiones a una representación estadística de la ciudadanía, no aborda los problemas intrínsecos que supone este depósito de confianza. A lo sumo, se puede suponer que su apuesta por la diversidad de los cuerpos funcionales y cooperativos son suficientes salvaguardas como para llevar a cabo la mejor toma de decisiones, excluyéndose de facto cualquier tipo de responsabilidad por malas prácticas políticas. En cuanto al componente ético de su propuesta sigue las mismas pautas: se presupone. Burnheim reduce el componente ético, la justicia y el bien común, al principio de reciprocidad durante el proceso de negociación. La negociación implica la construcción de paquetes integrales a partir de la explotación de posibilidades, en los cuales prevalecerían las preferencias reales de todos los implicados en sus respectivos cometidos. La pregunta que suscita es ¿se puede negociar la justicia y el bien común?

La propuesta de Goodwin defiende que la justicia se puede lograr por lotería. Aunque no encuentra perfecta la justicia por lotería, sí la ve mejor que las teorías de la justicia existentes. Pero ¿qué tipo de justicia? La justicia distributiva; es decir, cada individuo experimentará a lo largo de su vida una variedad de bienes sociales y una selección representativa de los males sociales. El alcance de la propuesta de Goodwin no se limita a la política y a la economía, sino a todas las manifestaciones sociales. Su propuesta no aborda, de manera explícita, el tema de la responsabilidad política de los sorteados al ocupar los cargos públicos. No obstante, presenta la "lotería penal" con diferentes grados de castigo para los delincuentes. En cuanto al componente ético se reduce a que con el sorteo se puede alcanzar la igualdad y la justicia, y que la sociedad se tiene que regir por una justicia basada en valores.

La responsabilidad y la ética son dos pilares fundamentales para la profundización democrática. Si bien ambos autores buscan su referente en la democracia ateniense, se echa en falta una reflexión sobre estos valores tan trascendentales. Sin embargo, si tenemos en cuenta que sus propuestas nacen como utopías, se puede entender que no sean un tratado teórico sobre responsabilidad y ética. La sociedad que imaginan no precisa de esos valores. Simplemente, porque cambian una sociedad de su época dominada por un capitalismo agresivo, donde prima la sociedad del individualismo egoísta, por otra basada en el comunitarismo, donde la sociedad apuesta por valores colectivos frente a los personales. La justica y el bien común frente a las injusticias y los intereses particulares. Sin embargo, esto no les exime de no haber tratado adecuadamente la ética cívica y la educación democrática a través de un proceso de aprendizaje de la ciudadanía, ya que estos, como otros conocimientos, no surgen de manera espontánea en el individuo, sino que requieren de un esfuerzo estructural e institucional al que no se puede renunciar.

\section{Aplicaciones prácticas contemporáneas del uso del sorteo.}

La erosión de la confianza de la ciudadanía en sus representantes y partidos políticos, las instituciones democráticas y las elecciones periódicas destacan por ser de los fenómenos más analizados en la ciencia política durante las últimas décadas ${ }^{89}$. La paulatina disminución de la confianza repercute en la legitimidad que adquiere la democracia representativa de la ciudadanía, que se manifiesta en indicadores como una elevada abstención en los comicios, la perdida de afiliación de los partidos políticos o el descenso de la lealtad de partido entre otros ${ }^{90}$. Colin Crouch denomina posdemocracia al momento que están atravesando las democracias representativas actuales. A su juicio, la democracia liberal se ha convertido en un espectáculo del juego electoral donde, si bien se posibilita que a través de las elecciones se pueden cambiar los gobiernos, el debate electoral público se centra en un espectáculo directamente controlado por equipos rivales de profesionales expertos en técnicas de persuasión, que predisponen las cuestiones a tratar, lo que provoca que la mayor parte de la ciudadanía desempeñe un protagonismo pasivo, inactivo e incluso apático. En este juego electoral la política real se lleva a cabo entre bambalinas, donde solo participan los gobiernos electos y unas élites que defienden los intereses de las empresas ${ }^{91}$. Es en este contexto en el que emerge el uso del sorteo en política, llevándose a cabo numerosas experiencias democráticas, con el objetivo de incentivar la participación ciudadana como elemento crucial para restaurar la legitimidad democrática del sistema político.

En las últimas décadas, se han llevado a cabo numerosas experiencias democráticas que han incorporado el sorteo en política, donde la participación ciudadana es esencial para mejorar el sistema político, y se apuesta por la igualdad política de la ciudadanía en el debate público y en la toma de decisiones ${ }^{92}$. Si bien las experiencias participativas y deliberativas diseñadas por sorteo están proliferando de manera exponencial, no son nuevas. A principios de la década de los 70, "los jurados ciudadanos" comenzaron a implementar la selección por

\footnotetext{
89 Domingo García-Marzá, "El valor democrático de la sociedad civil: una respuesta a la desafección”: Themata. Revista de Filosofia, n. 52 (2015), pp. 94-98.

90 Van Reybrouck, Contra las elecciones, pp. 17-20; Simon Tormey, The End of Representative Politics, Polity Press, Cambridge, 2015.

Colin Crouch, Posdemocracia, Taurus, Madrid, 2004, p.11.

Sintomer, Sorteo y política, p. 26.
} 
sorteo para la política, casi simultáneamente en Alemania y en los Estados Unidos ${ }^{93}$. A finales de los años ochenta, el modelo de las "conferencias de consenso" empezó a implementarse en Dinamarca para debatir asuntos tecnológicos y científicos ${ }^{94}$. En este mismo período, en los Estados Unidos surgieron "las encuestas deliberativas" aplicadas a ciertos asuntos, en las que participaban y deliberaban cientos de ciudadanos ${ }^{95}$. La novedad de estas experiencias deliberativas es que se basan en muestras representativas de la población seleccionadas al azar, favoreciendo que la ciudadanía común participe en los asuntos públicos. Durante las décadas de los noventa y los dos mil, estos mecanismos se aplicaron en diversos países promoviendo nuevas y diversas experiencias: la Convención Constitucional de Australia en 1998 y la Asamblea Ciudadana de la Columbia Británica (Canadá) en 2005. La tendencia se ha incrementado durante la década de 2010 en países como Islandia e Irlanda, con resultados dispares ${ }^{96}$. No obstante, se pone de manifiesto que la idea de recuperar el sorteo para la política está calando en el imaginario colectivo de muchos países.

La Asamblea Ciudadana de la Columbia Británica es el proceso más conocido, en el cual la ciudadanía fue seleccionada por sorteo. En 2004, esta provincia canadiense inició un proceso deliberativo con el objetivo de encargar a una asamblea ciudadana la reforma electoral. Esta asamblea estaba compuesta por 160 ciudadanos seleccionados aleatoriamente, y su dictamen se votaría más tarde en referendo. El 17 de mayo de 2005, la Columbia Británica estuvo cerca de convertirse en la primera jurisdicción política a nivel mundial en cambiar su sistema electoral a través de un proceso de deliberación ciudadana ${ }^{97}$. En 2006, Ontario (Canadá) también llevó a cabo un proceso análogo para reformar la ley electoral, invitando a participar a un grupo aleatorio de ciudadanos. Del conjunto de candidatos que formalizaron su participación se seleccionaron al azar una muestra representativa de 103 personas, en el cual era imprescindible respetar la pirámide de edad ${ }^{98}$. Finalmente, el referéndum no apoyó la propuesta de la Asamblea sobre la reforma electoral. En 2010, en Islandia se promovió desde el gobierno un Foro Nacional que reguló las bases de un Consejo Constitucional, con el mandato de redactar una nueva constitución. Este foro estaba compuesto por 950 personas seleccionadas aleatoriamente del registro electoral. Más tarde, el Parlamento islandés, apoyándose en el informe de este foro, creó un nuevo organismo compuesto por 25 delegados seleccionados por elección personal directa, que llevó a cabo un borrador constitucional. En octubre de 2012, se celebró un referéndum constitucional no vinculante, en cual se votó favorablemente la propuesta de Constitución. Sin embargo, los vencedores de las elecciones de 2013 decidieron no implementar la decisión popular ${ }^{99}$.

Una mención especial merece el caso de Irlanda. El gobierno irlandés promovió una Convención Constitucional, que estaba compuesta por 100 personas: 66 ciudadanos comunes, 33 miembros del Parlamento y un presidente elegido por consenso. La selección la realizó una empresa independiente, que llevó a cabo una selección aleatoria en base al registro electoral, y bajo unas premisas previas: sexo, edad, procedencia geográfica, nivel educativo y estatus socioeconómico ${ }^{100}$. El 22 de mayo de 2015 se celebró un referéndum para permitir el matrimonio entre personas del mismo sexo ${ }^{101}$. Esta fue la primera vez en la historia de Irlanda en la que se convocó un referéndum, a instancias de un proceso deliberativo en el cual se implicaba a ciudadanos comunes, y el primero en el mundo en haber tenido éxito ${ }^{102}$.

Tras el éxito alcanzado en un tema tan controvertido para la sociedad irlandesa como era el matrimonio homosexual, unos años más tarde se adoptó la misma estrategia y se propuso una nueva Asamblea de Ciudadanos para abordar el tema del aborto ${ }^{103}$. En 2017, se creó la Asamblea de Ciudadanos presidida por la jueza Mary Laffoy y compuesta por 99 ciudadanos seleccionados aleatoriamente. La Asamblea votó favorablemente la recomendación, que quedó en manos del Parlamento, creando el Comité Conjunto del Parlamento sobre la Octava Enmienda. El 25 de mayo de 2018 se celebró el referéndum para llevar a cabo la abolición del aborto a través de derogar la octava enmienda de la Constitución. La victoria a favor de derogar la octava enmienda de la Constitución fue aplastante consiguiendo un $66,4 \%$ de los votos, allanando el camino para la legalización del aborto ${ }^{104}$.

Ibid., p. 33 .

94 Marila Lázaro, Micaela Trimblee, Alejandra Umpiérrez, Ana Vasquez y Gustavo Pereira, Juicios Ciudadanos en Uruguay: dos experiencias de participación pública deliberativa en ciencia y tecnología, Universidad de la República: PNUD, Uruguay, 2013 , p. 23.

5 James Fishkin, Democracia y deliberación. Nuevas perspectivas para la reforma democrática, Editorial Ariel, Barcelona, 1995.

96 Roberto Gargarella, "De la democracia participativa a la deliberación inclusiva: "minipúblicos", loterías y Constituciones elaboradas por la ciudadanía (crowdsourced constitutions). Comentarios muy preliminares": Revista del Centro de Estudios Constitucionales, año V, n. ${ }^{\circ} 9$ (2019), p. 41.

97 Amy Lang, "But Is It for Real? The British Columbia Citizens' Assembly as a Model of State-Sponsored Citizen Empowerment": Politics \& Society, vol. 35 , n. ${ }^{\circ} 1$ (2007), p. 36.

98 Van Reybrouck, Contra las elecciones, p. 135.

99 Gargarella, "De la democracia participativa a la deliberación inclusiva", pp. 47-49.

100 David M. Farrell, Jane Suiter, Clodagh Harris y Kevin Cunningham, "The Effects of Mixed Membership in a Deliberative Forum: The Irish Constitutional Convention of 2012-2014”: Political Studies, vol. 68, n. ${ }^{\circ} 1$ (2020), pp. 3-4.

101 Fergus Ryan, "Ireland's Marriage Referendum: A Constitutional Perspective": DPCE online, vol. 22, n. 2 (2015), p. 1.

102 Johan A. Elkink, David M. Farrell, Theresa Reidy y Jane Suiter, "Understanding the 2015 Marriage Referendum in Ireland: Context, Campaign, and Conservative Ireland": Irish Political Studies, vol. 32, n. 3 (2017), p. 2.

103 Jane Suiter, David, David M. Farrell, Clodagh Harris y Eoin O’Malley, "La première Convention constitutionnelle irlandaise (2013-2014): un dispositive délibératif à forte légitimité?”: Participations, vol. 23, n. ${ }^{\circ} 1$ (2019), p. 141.

104 Mary Donnelly y Claire Murray, “Abortion Care in Ireland: Developing Legal and Ethical Frameworks for Conscientious Provision”: International Journal of Gynecology Obstetrics, vol. 148, n. ${ }^{\circ} 1$ (2020), p. 127. 


\section{Conclusiones}

El presente trabajo presentó y analizó las dos propuestas utópicas-democráticas de Burnheim y Goodwin, donde a grandes rasgos se expusieron sus concepciones sobre el uso del sorteo en política, desde la defensa de una sociedad con igualdad política hasta la crítica del fundamentalismo electoral y su promoción del profesionalismo y la formación de élites, que deslegitiman los valores de la democracia actual. A partir de la presentación de unos principios mínimos - que deberían acompañar al sorteo para potenciar la profundización democrática-, la conceptualización de utopía, y la relación entre el pensamiento utópico con las transformaciones de la ciencia política, se ha realizado una crítica de las potencialidades y limitaciones, en las que se ha intentado establecer los niveles de problematicidad de las dos propuestas utópicas. Posteriormente, se ha incluido una crítica constructiva sobre el sorteo, presentando algunas experiencias democráticas, donde la selección aleatoria constituía el eje principal para seleccionar a la ciudadanía común en la participación de la toma de decisiones políticas.

La democracia por sorteo se presenta entonces con mayor potencial para la inclusión de los intereses de la ciudadanía respecto a la democracia electoral, en la medida en que se funda, explícita o implícitamente, en ciertos compromisos colectivos para buscar la justicia y la igualdad política, capaces de hacer frente a distintos riesgos democráticos como el efecto nocivo de la profesionalización y el dominio de las élites que acaparan el poder en la esfera pública.

La presente conclusión no significa que la democracia por sorteo esté exenta de objeciones, ya que sus supuestos, al igual que la democracia electoral, tienen su propia problematicidad. Es decir, una vez el ciudadano ha sido seleccionado por sorteo entra de hecho en un proceso propicio para la manipulación por parte de poderes interesados. No obstante, si bien el representante electo puede ser revocado en los próximos comicios, pero no antes, el sorteado nunca legisla directamente, ya que prima la trasparencia de sus actos, siempre supervisados y ejecutados cooperativamente a través de diferentes órganos deliberativos. Si bien el riesgo de la corrupción no desaparece por completo, al menos, la influencia de poderes ajenos al proceso democrático tiene que lidiar con adversidades más difíciles de superar. Y, sobre todo, el sorteo se convierte en un instrumento eficaz y capaz de elevar a la ciudadanía común a cotas de participación y deliberación impensables bajo el procedimiento de la representación electoral, aumentando considerablemente la legitimidad y la profundización democrática.

Evidentemente, no se puede esperar que el sorteo por sí mismo sea la solución universal para todos los problemas que presentan las democracias representativas actuales y, por tanto, renunciar de pleno a la elección sería una propuesta demasiado atrevida o, siguiendo la línea de este artículo, utópica. Por todo ello, defiendo que las elecciones sean complementadas por mecanismos como el sorteo, la rotación, la limitación de mandatos, y la deliberación pública que, a mi parecer, pueden favorecer la legitimidad democrática. Y al incentivarse la participación ciudadana en la esfera pública, se haría frente al desafío de la apatía política que está instalando en nuestras sociedades. No cabe duda que la búsqueda de una sociedad mejor no depende del uso del sorteo o la elección, sino que es un problema estructural más difícil de acometer. Hay que pasar de una sociedad individualista a otra donde prime el interés general y el bien común, y esto es impensable sin una educación para la ciudadanía donde primen los valores cívicos. Pero abordar esto trasciende los propósitos de este trabajo. Sea como fuere, el debate sobre la idoneidad del sorteo en política no ha hecho más que empezar.

\section{Referencias bibliográficas}

Aristóteles, La Constitución de los Atenienses, Gredos, Madrid, 1984.

\section{— Política, Gredos, Madrid, 1988.}

Bachrach, Peter, Crítica de la teoría elitista de la democracia, Amorrortu editores, Buenos Aires, 1967.

Barber, Benjamin, Democracia fuerte, Editorial Almuzara, Córdoba, 2004.

Bakunin, Mijaíl, Dios y el Estado, El viejo topo, Barcelona, 2008.

Bouricious, Terrill G., "Democracy Through Multi-Body Sortition: Athenian Lessons for the Modern Day": Journal of Public Deliveration, vol. 9, art. 11, n. ${ }^{\circ} 1$ (2013), pp. 1-19. Disponible en: https://www.publicdeliberation.net/jpd/vol9/ iss1/art11 (12-1-2020).

Buchstein, Hubertus, "Countering the Democracy Thesis'- Sortition in Ancient Greek Political Theory": Redescripcions: Political Thought, Conceptual History and Feminist Theory, vol. 18, n. 2 (2015), pp. 126-157, DOI: http://doi. org/10.7227/R.18.2.2.

Burnheim, John, Is Democracy Possible? The alternative to electoral politics, University of California Press, California, 1985.

Callenbach, Ernest y Michael Phillips, A Citizen Legislature, Banyan Tree Books, Berkeley, 1985.

Cortina, Adela, Ciudadanos del mundo. Hacia una teoría de la ciudadanía, Alianza editorial, Madrid, 1997.

Crouch, Colin, Posdemocracia, Taurus, Madrid, 2004.

Delannoi, Gil y Oliver Dowlen, Sortition: Theory and Practice, Imprint Academic, Exeter, 2010. 
Donnelly, Mary y Claire Murray, “Abortion Care in Ireland: Developing Legal and Ethical Frameworks for Conscientious Provision”: International Journal of Gynecology Obstetrics, vol. 148, n. ${ }^{\circ} 1$ (2020), pp. 127-132, DOI: https://doi. org/10.1002/ijgo.13025.

Duverger, Maurice, Los partidos políticos, Fondo de Cultura Económica, México, 2012.

Elkink, Johan A., David M. Farrell, Theresa Reidy y Jane Suiter, "Understanding the 2015 Marriage Referendum in Ireland: Constitutional Convention, Campaign, and Conservative Ireland": Irish Political Studies, vol. 32, n. ${ }^{\circ} 3$ (2017), pp. 361-381, DOI: https://doi.org/10.1080/07907184.2016.1197209.

Farrell, David, Jane Suiter, Clodagh Harris y Kevin Cunningham, "The Effects of Mixed Membership in a Deliberative Forum: The Irish Constitutional Convention of 2012-2014”: Political Studies, vol. 68, n. ${ }^{\circ} 1$ (2020), pp. 54-73, DOI: https://doi.org/10.1177/0032321719830936.

Feenstra, Ramón A., "Democracia y elección por sorteo en las nuevas formaciones políticas: teorías políticas clásicas y contemporáneas": Daimon. Revista Internacional de Filosofía, n. ${ }^{\circ} 72$ (2017), pp. 205-219, DOI: https://doi. org $/ 10.6018 / 295601$.

Ferrater Mora, José, "Utopía”, Diccionario de filosofía, tomo II, 5a ed., Editorial Sudamericana, Buenos Aires, 1964.

Fischer, Frank, Democracy \& Expertise. Reorienting Policy Inquiry, Oxford University Press, Oxford, 2009.

Fishkin, James, Democracia y deliberación. Nuevas perspectivas para la reforma democrática, Editorial Ariel, Barcelona, 1995.

Ganuza, Ernesto y María Menéndez, “Te ha tocado? El sorteo llega a la política de Madrid”: Recerca. Revista de pensament $i$ anàlisi, n. ${ }^{\circ}$ 25(1) (2020), pp. 1-15, DOI: https://doi.org/10.6035/Recerca.2020.25.1.6.

García-Marzá, Domingo, "El valor democrático de la sociedad civil: una respuesta a la desafección": Themata. Revista de Filosofía, n. 52 (2015), pp. 93-109, DOI: https://dx.doi.org/10.12795/themata.2015.i52.05.

Gargarella, Roberto, "De la democracia participativa a la deliberación inclusiva: minipúblicos', loterías y Constituciones elaboradas por la ciudadanía (crowdsourced constitutions). Comentarios muy preliminares": Revista del Centro de Estudios Constitucionales (Centro de Estudios Constitucionales de la Suprema Corte de Justicia de la Nación, México), año V, n. 9 (2019), pp. 39-63.

Goodwin, Barbara, Justice by Lottery, University of Chicago Press, Chicago, 1992.

Guerrero, Alexander A., “Against Elections: The Lottocratic Alternative”: Philosophy \& Public Affairs, vol. 42 (2014), pp. 135-178. Disponible en: https://ssrn.com/abstract=2488791 (8-1-2020).

Habermas, Jürgen, Facticidad y validez, Trotta, Madrid, 1998.

Hansen, Morgens, The Athenian Democracy in the Age of Demosthenes: Structure, Principles, and Ideology, University of Oklahoma Press, Oklahoma, 1999.

Held, David, Modelos de democracia, Alianza editorial, Madrid, 1991.

Kumar, Krishan, "El pensamiento utópico y la práctica comunitaria: Robert Owen y las comunidades owenianas": Política y sociedad, n. 11 (1992), pp. 123-143.

_ - "Pensar utópicamente: política y literatura": Revista internacional de filosofía política, n. ${ }^{\circ} 29$ (2007), pp. 65-80.

Landemore, Hélène, "Deliberation, Cognitive Diversity, and Democratic Inclusiveness: an Epistemic Argument for the Random Selection of Representatives": Synthese, vol. 190, n. 7 (2013), pp. 1209-1231, DOI: https://doi.org/10.1007/ s11229-012-0062-6.

Lang, Amy, "But Is It for Real? The British Columbia Citizens' Assembly as a Model of State-Sponsored Citizen Empowerment": Politics \& Society, vol. 35, n. ${ }^{\circ} 1$ (2007), pp. 35-70, DOI: https://doi.org/10.1177/0032329206297147.

Lázaro, Marila, Micaela Trimble, Alejandra Umpiérrez, Ana Vasquez y Gustavo Pereira, Juicios Ciudadanos en Uruguay. Dos experiencias de participación pública deliberativa en ciencia y tecnología, Universidad de la República: PNUD, Uruguay, 2013.

Mair, Peter, Gobernando el vacio: la banalización de la democracia occidental, Alianza editorial, Madrid, 2015.

Manin, Bernard, Los principios del gobierno representativo, Alianza editorial, Madrid, 1998.

Marx, Karl y Friedrich Engels, Manifiesto Comunista, Alianza editorial, Madrid, 2002.

Michels, Robert, Los partidos políticos. Un estudio sociológico de las tendencias oligárquicas de la democracia moderna, Amorrortu editores, Buenos Aires, 2 vols., 1969-1972.

Misseri, Lucas E., "Vigencia de la utopía en el siglo XXI: Análisis del proyecto de barrio intercultural en San Martín de los Andes": Estudios de Filosofía Práctica e Historia de las Ideas, vol. 17, n. 2 (2015), pp. 57-68.

Moro, Tomas, Tomasso Campanella y Francis Bacon, Utopías del Renacimiento, estudio preliminar por Eugenio Imaz, trad. de Agustín Millares Carlo, Agustín Mateos, Margarita V. de Robles, Fondo de Cultura Económica, México, 2005.

Pateman, Carole, Participation and Democratic Theory, Cambridge University Press, Cambridge, 1970.

Pitkin, Hanna F., El concepto de representación, Centro de Estudios Constitucionales, Madrid, 1985.

Platón, Diálogos IV República, Gredos, Madrid, 1988.

Proudhon, Pierre, Escritos Federalistas, Akal, Madrid, 2011.

Real Academia Española, "Utopía”, Diccionario de la lengua española, 23ª ed, 2018.

Ryan, Fergus, "Ireland's Marriage Referendum: A Constitutional Perspective": DPCE online, vol. 22, n. ${ }^{\circ} 2$ (2015). Disponible en: http://www.dpceonline.it/index.php/dpceonline/article/view/168 (20-1-2020). 
Saramago, José, “¿Qué es exactamente la democracia?”: Le Monde Diplomatique, publicado en Edición Cono Sur, n. ${ }^{\circ} 62$ (2004), pp. 22-23. Disponible en: https://www.eldiplo.org/062-hambre-en-el-pais-de-la-tierra/que-es-exactamente-lademocracia/.

Sartori, Giovanni, Teoría de la democracia 2. Los problemas clásicos, Alianza editorial, Madrid, 1988.

Schmitter, Philippe C., "Veinticinco años, veinticinco hallazgos": PostData, vol. 16, n. ${ }^{\circ} 1$ (2011), pp. 11-25. Disponible en: https://dialnet.unirioja.es/servlet/articulo?codigo=3702338 (7-1-2020).

Schumpeter, Joseph, Capitalismo, socialismo y democracia, vol. II, Folio, Barcelona, 1996.

Servier, Jean, Historia de la utopía, Monte Ávila Editores, Barcelona, 1969.

Sinclair, R. K., Democracia y participación en Atenas, Alianza editorial, Madrid, 1999.

Sintomer, Yves, "Sorteo y política: ¿de la democracia radical a la democracia deliberativa?: Daimon. Revista Internacional de Filosofía, n. 72 (2017), pp. 25-43, DOI: http://dx.doi.org/10.6018/daimon/295531.

Suiter, Jane, David M. Farrell, Clodagh Harris y Eoin O’Malley, "La première Convention constitutionnelle irlandaise (2013-2014): un dispositif délibératif à forte légitimité ?”: Participations, vol. 23, n. ${ }^{\circ} 1$ (2019), pp. 123-146. Disponible en: https://www.cairn.info/revue-participations-2019-1-page-123.htm.

Sutherland, Keith, People's Parliament, Academic, Exeter, 2008.

Tormey, Simon, The End of Representative Politics, Polity Press, Cambridge, 2015.

Tucídides, Historia de la Guerra del Peloponeso, Biblioteca Clásica Hernando, Madrid, 1952.

Van Reybrouck, David, Contra las elecciones. Cómo salvar la democracia, Taurus, Barcelona, 2017.

Weber, Max, "La política como vocación” (1919), en El político y el cientifico, intr. de Raymond Aron, trad. Francisco Rubio Llorente, Alianza editorial, Madrid, 2003, pp. 81-180. 